\title{
A MODELAGEM E A SIMULAÇÃO COMPUTACIONAL COMO FERRAMENTAS TECNOLÓGICAS NO ENSINO DE FÍSICA
}

\author{
Jefferson Oliveira do Nascimento ${ }^{1}$ \\ Italo Gabriel Neide ${ }^{2}$ \\ Sônia Eliza Marchi Gonzatti ${ }^{3}$ \\ Marcelo Albano Moret ${ }^{4}$
}

\begin{abstract}
Resumo: A Física é uma disciplina de fundamental importância, seja no ensino médio regular, na educação profissional ou em muitos currículos ao nível superior. Porém, devido à abordagem pedagógica com que é apresentada para os alunos, o resultado muitas vezes não corresponde a um aprendizado significativo, com reprovaçôes e evasões do ambiente de aprendizagem. Em nossa prática profissional, percebemos que os discentes nestes três níveis de ensino apresentavam concepçóes equivocadas em relação aos conhecimentos físicos relacionados ao fenômeno das estaçóes do ano. Este fato suscitou o desenvolvimento desta pesquisa com alunos do PROEJA, com o objetivo de identificar se há indícios de aprendizagem significativa dos conteúdos pelos alunos no ensino de Física por meio da utilização de ferramentas tecnológicas. Para isto, realizamos um estudo de caso por meio de uma intervenção pedagógica. As ferramentas tecnológicas escolhidas corresponderam a modelagem e a simulação computacional. $\mathrm{O}$ alicerce teórico cognitivo da presente pesquisa é a Teoria da Aprendizagem Significativa de David Ausubel. Ao fim, o objetivo de verificar indícios de aprendizagem significativa foi alcançado, indicando a possibilidade da modelagem e a simulaçáo computacional serem caracterizadas como materiais educacionais potencialmente significativos.
\end{abstract}

Palavras-chave: Ensino de física. Modelagem Computacional. Simulação Computacional. Estaçóes do Ano.

1 Doutorando em Modelagem Computacional e Tecnologia Industrial, Programa de Modelagem Computacional - Senai CIMATEC (Bolsista FAPESB).

2 Doutor em Física - UFRGS. Professor do Centro Universitário UNIVATES.

3 Doutora em Educação - PUCRS. Professora do Centro Universitário UNIVATES.

4 Doutor em Biofísica - UFRJ. Universidade do Estado da Bahia - UNEB. Programa de Modelagem Computacional - Senai CIMATEC. 


\title{
MODELLING AND COMPUTER SIMULATIONS AS TECHNOLOGICAL TOOLS IN PHYSICS EDUCATION
}

\begin{abstract}
Physics is a discipline of fundamental importance, whether in regular high school, vocational education or many curricula at the higher level. However, due to the pedagogical approach that is presented to the students, the result often does not correspond to a meaningful learning, with disapprovals and evasions of the learning environment. In our professional practice, we noticed that the students in these three levels of education had misconceptions regarding the physical knowledge related to the phenomenon of the seasons. This fact led to the development of this research with PROEJA students, with the objective of identifying if there is evidence of significant learning of the contents by students in the teaching of Physics through the use of technological tools. For this, we carried out a case study through a pedagogical intervention. The technological tools chosen corresponded to modeling and computational simulation. The theoretical cognitive foundation of this research is David Ausubel's Significant Learning Theory. Finally, the objective of verifying significant learning cues was reached, indicating the possibility of modeling and computational simulation being characterized as potentially significant educational materials.
\end{abstract}

Keywords: Physics Education. Modeling Computer. Computer simulation. Season of the Year.

\section{INTRODUÇÁO}

O ensino de Física tem-se realizado na educação básica, frequentemente mediante a apresentação de conceitos, leis e fórmulas matemáticas, de forma desarticulada, distanciado do mundo vivido pelos alunos e professores e não só, mas também por isso, vazios de significado (BRASIL, 1999). Não obstante, desde os anos iniciais do ensino fundamental, a temática das estações do ano merece destaque no processo de ensino de aprendizagem, pois normalmente ocorre pela utilização de modelos equivocados, como o "modelo da distância", conforme preconiza Gonzatti (2008) e Nascimento (2015).

De acordo com Nascimento, Neide e Gonzatti (2016), este modelo resulta em uma trajetória de revolução equivocada da Terra ao redor do Sol, cuja forma é exageradamente elíptica. No caso da órbita da Terra, a excentricidade é muito próxima de zero $(0,016)$, o que nos permite concluir que o formato é quase circular e a diferença de distância entre periélio e afélio é de apenas de 3\% (KEPLER; SARAIVA, 2014). Este resultado se diferencia bastante dos valores de excentricidades encontrados em materiais didáticos utilizados em Ensino de Física, em que as elipses podem apresentar, em média, valores da ordem de 0,568 (NASCIMENTO, 2015). A temática das estações corresponde a um dos conhecimentos científicos que mais se destacam em ser aprendidos de forma equivocada (MOREIRA, 2013), pois, embora pertençam ao nosso cotidiano, sua compreensão exige a integração de diferentes conceitos, como por exemplo, situar a Terra como corpo cósmico e desenvolver um modelo tridimensional para o sistema Sol-Terra (NUSSBAUM, 1979; NASCIMENTO; NEIDE; GONZA'TTI, 2016).

Desta forma o presente artigo apresenta alguns resultados da dissertação de mestrado do primeiro autor cujo objetivo foi o de verificar indícios de 
aprendizagem significativa pelos alunos de uma turma de PROEJA (curso Técnico em Informática), no ensino do fenômeno astronômico das estações do ano. As ferramentas tecnológicas utilizadas foram a simulação e a modelagem computacional. O PROEJA é uma forma integrada entre Educação Profissional, Ensino Médio e Educação de Jovens e Adultos, sendo direcionada apenas para pessoas maiores de 18 anos (BRASIL, 2007). O estudo desenvolvido com eles e apresentado aqui, observou os pressupostos da pesquisa qualitativa, com a realização de um estudo de caso, por meio de uma intervenção pedagógica. A turma era constituída de trinta alunos, com idades entre vinte e cinco e cinquenta e cinco anos, sendo quatorze homens e dezesseis mulheres, pertencentes a uma escola de Educação Profissional Estadual localiza em Belém/PA.

Diferentemente do ensino médio regular, o PROEJA é formado por alunos diferenciados, que normalmente estão há certo tempo afastados do ambiente escolar (PEREIRA, 2011). Existem especificidades que devem ser pensadas na prática pedagógica docente, relativas a esta modalidade de ensino (IBID, 2011). Ao retomarem os estudos, fazendo a opção por cursar o ensino médio integrado ao ensino técnico, deve-se ter um olhar especial em relação às práticas pedagógicas desenvolvidas e a forma de como os conteúdos serão abordados, haja vista a elevada complexidade que há neste retorno às aulas. Estes fatores contribuíram para nossa escolha de investigação na temática de estações do ano com o público do PROEJA.

\section{AS ESTAÇÓES DO ANO E A TEORIA DE AUSUBEL}

Aprendizagem significativa é um processo cujo produto resultante é a aquisição de novos significados pelo aluno (AUSUBEL, 2003). Ao longo do processo de aprendizagem, uma nova informação interage de maneira substantiva ou não literal (não ocorrendo em seu sentido exato e preciso), e também de forma não arbitrária (não será com qualquer ideia prévia que o novo conhecimento irá interagir), com um aspecto importante na estrutura cognitiva já pertencente ao aluno. Essa estrutura preexistente recebe o nome de conceito subsunçor ou subsunçor, uma tradução literal do termo em inglês subsumers, a qual está presente no arcabouço cognitivo do aluno (MOREIRA, 2009). Moreira (2010, p. 10) nos remete ao pensamento de que os subsunçores são: “[...] conhecimentos prévios especificamente relevantes para que os materiais de aprendizagem ou, enfim, os novos conhecimentos sejam potencialmente significativos".

Desta forma, a fim de verificarmos indícios de aprendizagem significativa dos alunos do PROEJA na temática das estações do ano, realizamos inicialmente uma busca na literatura científica para verificarmos possíveis respostas em relação ao conceito subsunçor necessário para que fosse possível o ensino das estações do ano, conforme norte fornecido pela teoria de Ausubel. A síntese e resposta desta pesquisa está demonstrada na Figura 1: 
Figura 1 - O conceito de Terra como corpo cósmico indicado por autores como conceito subsunçor para o ensino de estações do ano.

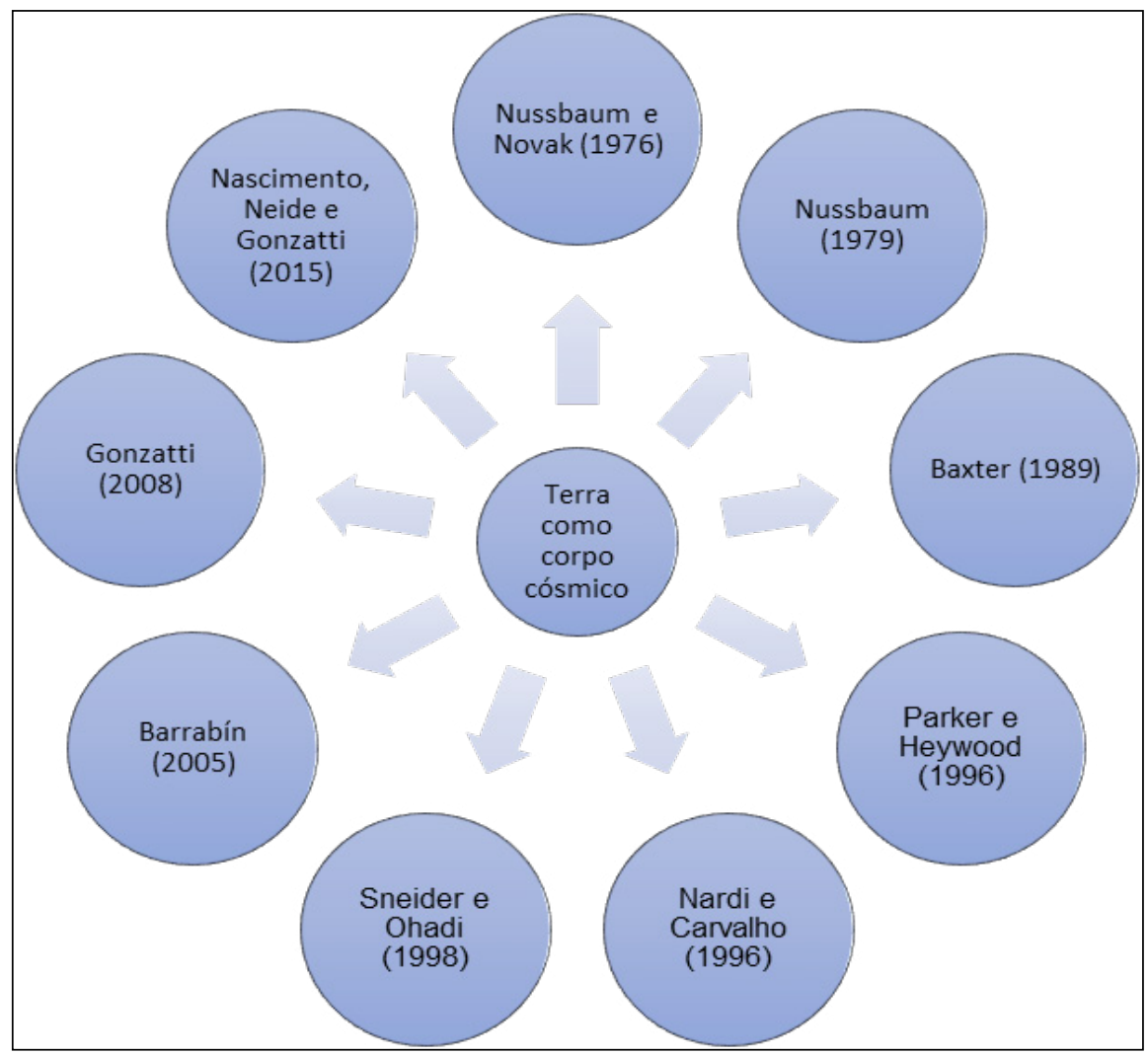

Fonte: Adaptado de Nascimento (2015) e Nascimento, Neide e Gonzatti (2016).

Os autores apresentados na Figura 1, indicam que a concepção de Terra como corpo cósmico é um conceito subsunçor que deve ser anteriormente abordado em relação ao ensino das estações do ano. Assim "[...] a Terra deve ser considerada a partir da interação gravitacional dela com o Sol, assumindo-se esse conceito como alicerce fundamental para o aprendizado dos fenômenos astronômicos" (NASCIMENTO; NEIDE; GONZATTI, 2016, p. 126). Desta forma o ensino do fenômeno astronômico das estações do ano, que corresponde a um novo conhecimento por parte do aluno, deve ser ligado/incorporado ao conceito subsunçor Terra como corpo cósmico - contido na estrutura cognitiva do aluno de forma não literal e não arbitrária, para que o aprendizado seja significativo.

Os fundamentos da abordagem de Terra como corpo cósmico são os que estão relacionados à passagem do tempo, assim como os que envolvem uma teoria sobre o posicionamento da Terra no cosmos, sua interação com outros astros, especialmente Sol e Lua, seu campo gravitacional, aspectos que estão ligados a um modelo de Terra como corpo cósmico (GONZATTI, 2008; NASCIMENTO 2015). 
Este fato irá propiciar a relação de seu formato e suas interações gravitacionais, promovendo o entendimento coerente entre a Terra e Universo em conformidade com o atual modelo científico (GONZATTI, 2008; NASCIMENTO 2015). Em outras palavras:

Tratar a Terra como corpo cósmico significa abordá-la por meio de sua forma, seu campo gravitacional, seus movimentos e os fenômenos astronômicos decorrentes desses movimentos e da configuração do sistema Terra-Sol-Lua, como por exemplo, dias, noites, estações do ano, fases e eclipses lunares, ou seja, a sua interação com outros astros cósmicos (GONZATTI apud NASCIMENTO; NEIDE; GONZATTI, 2016).

Considerando a ausência de subsunçores, uma possibilidade para sua obtenção ocorre por meio dos organizadores prévios. Moreira (2011, p. 163) nos esclarece que: "Os organizadores prévios são materiais introdutórios apresentados antes do material a ser aprendido em si". Não se devem tratar os organizadores prévios como meras comparações introdutórias, já que identificam o conteúdo relevante na estrutura cognitiva do aluno, enfocando a importância deste para o novo material a ser aprendido, com um alto grau de abstração. Os organizadores prévios destacam a ideia central do novo material de aprendizagem, promovendo assim uma contextualização proposital para aprender de forma significativa o novo conhecimento (MOREIRA, 2013). Na presente pesquisa, foram realizados quatro encontros com quatro horas/aulas cada, como organizadores prévios, conforme detalharemos mais adiante.

Ao apresentarmos um novo conteúdo ao aluno, ao serem realizadas as abordagens como proposições, ideias intuitivas e conceitos, estas deverão ocorrer primeiramente de forma ampla e geral, e após a sua consolidação pelo aluno, as mesmas deverão ser apresentadas progressivamente de forma mais específica (AUSUBEL, 2003). Este pensamento é denominado de diferenciação progressiva, e que conforme Moreira (2013, p. 74):

[...] como princípio programático da matéria de ensino, significa que ideias, conceitos, proposições mais gerais e inclusivos do conteúdo devem ser apresentados no início do ensino e, progressivamente, diferenciados, ao longo do processo, em termos de detalhes e especificidades. Do ponto de vista cognitivo, é o que ocorre com determinado subsunçor à medida que serve de ancoradouro para novos conhecimentos em um processo interativo e dialético.

Quanto à reconciliação integradora ou integrativa, Moreira (2011, p. 112) nos diz que: "[...] é o princípio segundo o qual a instrução deve também explorar relações entre ideias, apontar similaridades e diferenças importantes e reconciliar discrepâncias reais ou aparentes", ou seja, o material instrucional apresentado ao aluno deve facilitar a aprendizagem ao possibilitar que ocorra interação entre as ideias já consolidadas na estrutura cognitiva com as novas ideias, verificando semelhanças e diferenças diante do novo conhecimento. Tanto a fenômeno da diferenciação progressiva quanto a reconciliação integradora foram verificadas 
durante a intervenção pedagógica com a turma do PROEJA, nos dados apresentados neste artigo.

\section{FERRAMENTAS TECNOLÓGICAS UTILIZADAS NO ENSINO DE ESTAÇÓES DO ANO}

Para Araujo (2002, 2005) e Nascimento (2015) uma metodologia possível de ser abordada no Ensino de Física é a utilização da modelagem e a simulação computacional. Os autores discutem que estas propostas didáticas envolvendo o uso de computadores, são instigadas devido ao surgimento de softwares cada vez mais elaborados, na tentativa de facilitar a construção do conhecimento por parte do estudante. Como o desenvolvimento desta pesquisa é com alunos pertencentes ao Curso Técnico em informática, na forma PROEJA, pressupõe-se que se utilizando diferentes materiais didáticos, alicerçados na interação com o computador, poderão se apresentar como materiais potencialmente significativos. Há uma probabilidade deste fato possibilitar, em alguma medida, a aprendizagem da temática das estações do ano.

Para facilitar os processos de ensino e de aprendizagem e obter um ganho real de tempo em frente ao computador, a modelagem computacional das estações do ano foi desenvolvida por meio do Software Modellus, que concentra a aprendizagem em atividades que necessitam fundamentalmente dos conceitos de Educação em Ciências e Matemática (TEODORO; NEVES, 2011). Nesse sentido, Representação Múltipla e Manipulação direta são características importantes no Modellus. A primeira consiste no fato de se poder criar, ver e interagir com representações analíticas, analógicas e gráficas de objetos matemáticos (NASCIMENTO, 2014). A segunda, manipulação direta, significa que o usuário pode trabalhar diretamente com todos os tipos de objetos que aparecem na tela do computador, sem a necessidade de conhecimento em uma determinada linguagem de programação, ou seja, os objetos podem ser manipulados de forma direta por obedecerem ao modelo matemático trabalhado (TEODORO; NEVES, 2011).

Os materiais utilizados nesta pesquisa, referente à simulação computacional, constituem-se em objetos de aprendizagens. Conforme Arantes, Miranda e Studart (2010, p. 27) os objetos constituem "recursos digitais em diferentes formatos: áudio, vídeo, animação e simulação computacional com certas características específicas no processo de ensino e aprendizagem". Diante dos repositórios de objetos de aprendizagem disponíveis na internet, a nossa escolha se deu por meio da utilização das simulações interativas e gratuitas do Projeto Physics Educacional Technology (PhET) da Universidade do Colorado (disponíveis em https://phet.colorado.edu/pt_BR/).

Neste artigo diferenciamos simulação e modelagem computacional pela interação que o aluno tem com o modelo matemático presente em sua execução. De acordo como em Araujo $(2002,2005)$ e Nascimento (2015) na simulação de um determinado modelo físico, é permitido apenas inserir valores e alterar parâmetros e, consequentemente, verificar os resultados em relação as variáveis inseridas. Já na 
modelagem, mesmo em caráter exploratório, é possível alterar a estrutura básica das equações matemáticas que o constituem o modelo computacional.

\section{PERCURSOS METODOLÓGICOS}

Para realizarmos esta investigação, alicerçamo-nos em pressupostos da pesquisa qualitativa, por meio de um estudo de caso. A pesquisa também foi definida como intervencionista, já que a mesma teve como foco principal se interpor e interferir na realidade dos alunos estudados, a fim de que ocorresse a possibilidade de modificá-la durante todo o processo (VERGARA, 2004). Iniciamos esta investigação com a aplicação de um pré-teste semiestruturado, para verificarmos os conhecimentos prévios dos alunos e nortear o desenvolvimento da intervenção. Ressaltamos que neste artigo não objetivamos discutir os resultados desta etapa inicial de averiguação. $\mathrm{Na}$ sequência, as atividades ocorreram da forma descrita no Quadro 1, finalizando com um pós-teste (também não discutido neste artigo).

Ratificamos que neste artigo, descrevemos duas aulas da intervenção pedagógica que ocorreram com a utilização de ferramentas tecnológicas. Essas aulas foram decorrentes do estudo de caso referente à dissertação de mestrado do primeiro autor deste artigo. Nas duas aulas apresentadas aqui, utilizamos dois questionários semiestruturados, um para a atividade de simulação e o outro para a de modelagem computacional, contendo perguntas analítico-expositivas, as quais descrevemos na próxima secção. Podemos inferir que a pesquisa aqui apresentada, está organizada em três partes, conforme o Quadro 1:

Inicialmente, foram realizados quatro encontros como organizadores prévios (cada um com duração de $4 \mathrm{~h} /$ aula), nas quais abordamos os conteúdos correspondentes aos conhecimentos prévios necessários para o aprendizado das estações do ano (subsunçores). Essas aulas ocorreram de forma expositiva. $\mathrm{Na}$ sequência, realizamos as aulas práticas (4h / aula) de exploração da atividade de simulação computacional utilizando o Software My Solar Systems, para o estudo da Lei da Gravitação Universal e Leis de Kepler. Após as aulas utilizando simulação computacional, realizamos as aulas práticas das atividades de modelagem computacional (4 h / aula) utilizando o Software Modellus, para o estudo das estações do ano.

Realizamos as análises das respostas dos alunos nos questionários respondidos, nas aulas que ocorreram com a atividade de modelagem e simulação computacional. Descreveremos na sequência os resultados obtidos nessas atividades e utilizaremos a seguinte denominação: Aluno 1, como A1, Aluno 2, como A2 e assim sucessivamente, em que os termos "alunos" substituem o nome deles e o número é o atribuído conforme a ordem alfabética, conforme inspirados em Nascimento, Neide e Gonzatti (2016). Ratificamos que os discentes participantes da pesquisa são de uma turma do PROEJA Técnico em Informática, em uma escola de Educação Tecnológica em Belém/PA. Dos trinta alunos, quatorze são homens e dezesseis mulheres, com faixa etária entre vinte e cinco e cinquenta e cinco anos. 


\section{ANÁLISES DOS DADOS DA ATIVIDADE 1 - ESTUDO DAS LEIS DE KEPLER E DA LEI DA GRAVITAÇÁO UNIVERSAL}

Após a realização das aulas introdutórias utilizadas como organizadores prévios, conforme a Teoria da Aprendizagem Significativa de Ausubel, foram desenvolvidas as atividades tecnológicas para a abordagem das estações do ano. Neste artigo, vamos detalhar duas delas. A primeira atividade foi desenvolvida utilizando o Software My Solar System (Figura 1) para o estudo das Leis de Kepler e Lei da Gravitação Universal de Newton.

Figura 1 - Software My Solar System

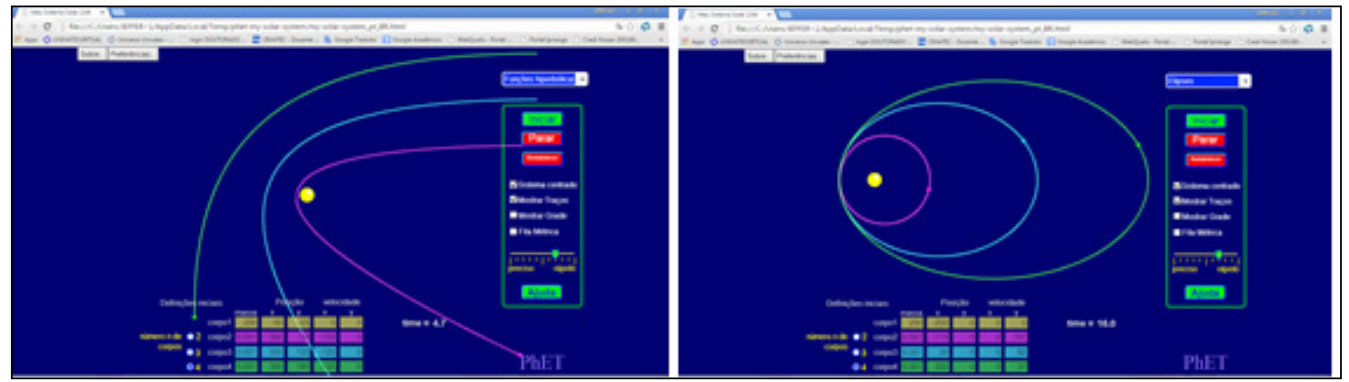

Fonte: do software.

A primeira questão do roteiro de atividades solicitava que os alunos reproduzissem a visualização da simulação solicitada, que descrevia o movimento de translação da Terra ao redor do Sol. Todos os alunos desenharam de forma coerente com a simulação. A segunda questão abordava se a trajetória visualizada na segunda simulação realizada poderia descrever o sistema Sol-Terra. Essa simulação apresentava uma trajetória elíptica, cuja excentricidade é extremamente baixa, tendendo a um movimento circular. Apresentamos algumas as respostas dos alunos, como a do A12 e a do A21, respectivamente: "Sim, a terra continua girando ao redor do sol, significa que é uma elipse", "Sim. Porque existe uma trajetória elíptica e a excentricidade muda".

Conforme Tipler e Mosca (2006), a excentricidade para a trajetória da órbita da Terra ao redor do Sol, apresenta um valor baixo, 0,016, o que torna essa forma geométrica praticamente circular. Ao observar as respostas dos alunos, percebemos que associaram a trajetória do movimento de revolução da Terra, com o formato elíptico de baixa excentricidade, conforme havia sido discutido durante as aulas teóricas (e também com a atividade de simulação entre Sol, Terra e eixo de inclinação, para que pudessem interagir com um modelo tridimensional). De acordo com Moreira (2011) essas argumentações dos discentes apresentam indicativos do estabelecimento de relações entre elementos do conteúdo apresentado em sala: a trajetória de revolução e o formato elíptico, correspondendo a possivelmente a reconciliação integradora, na Teoria de Ausubel. 
O penúltimo questionamento da segunda questão, solicitava que os discentes respondessem o valor da diferença de distância do periélio e afélio em relação ao Sol, em que a maioria dos alunos (dezesseis) responderam de forma coerente cientificamente. O último questionamento, requeria dos discentes que explicassem se as estações verão e inverno eram consequências das posições periélio e afélio. Para os alunos A6, A21, A24 e A25, suas respostas respectivamente, são transcritas aqui: "se dá [devido] ao eixo imaginário que tem uma inclinação de 23,5", que causa verão no extremo e em outro um intenso inverno"; "Não; a causa das estações do ano é a inclinação do planeta"; "Não, porque a causa das estações do ano, é o eixo imaginário, 23,5" e "Não porque a causa das estaçoes do ano é a inclinação da Terra em 23,5". Um total de dezesseis discentes apresentou este padrão de respostas observado.

Conforme Moreira (2013, p. 8) uma das concepções alternativas mais comuns no ensino de ciências, aprendidas de forma equivocada é o fato das pessoas acreditarem "[...] que no verão estamos mais próximos do sol e, no inverno, mais distantes, explicando assim as estações do ano". Nessa perspectiva, Gonzatti (2008) e Nascimento (2015) destacam que a real causa das estações é a inclinação do eixo imaginário da Terra, em aproximadamente $23,5^{\circ}$, em relação a normal do plano de revolução ao redor do Sol. Ao nos alicerçamos em Moreira (2013), é possível que as argumentações dos discentes, apresentadas acima, tragam elementos da reconciliação integradora, já que no início da pesquisa, como podemos verificar em Nascimento (2015), a maioria deles demonstrou desconhecimento na causa das estações.

$\mathrm{Na}$ terceira questão, o intuito foi de estudar a excentricidade de trajetórias de três planetas ao redor de uma estrela, de acordo com a segunda imagem da Figura 1. No primeiro questionamento, cabia ao aluno indicar e explicar quais das trajetórias se assemelharia a do planeta Terra. A seguir, apresentamos as repostas dadas pelos alunos A12, A15 e A24, respectivamente: "O rosa, pois sua excentricidade é muito baixa referentes aos outros", "rosa porque a excentricidade é muito baixa" e "O rosa, porque é o menos que tem excentricidade, muito baixa".

Nesta questão, vinte e quatro alunos apresentaram respostas coerentes cientificamente, optando pela trajetória de menor valor de excentricidade. Como último questionamento da terceira questão, cabia aos alunos explicarem se as estações do ano seriam afetadas pelas formas das trajetórias nos três planetas, devido as diferentes excentricidades. As respostas apresentadas pela maioria dos alunos nos fornecem possíveis indícios de aprendizagem. É o caso das argumentações dos alunos A21 e A24, respectivamente: "O rosa não interfere, o azul e o verde interferem por causa do alto valor da excentricidade", "apenas no azul e verde pelos exageros da excentricidade". Tal pensamento é alicerçado em Gonzatti (2008), Moreira (2013) e Nascimento (2015), pois apontam na direção de que muitas pessoas ainda admitem que o fenômeno das estações é dependente da distância Sol-Terra (modelo das distâncias), o que foi verificado nas repostas dos alunos no início da intervenção pedagógica - enfatizamos que estes resultados iniciais encontram-se em Nascimento (2015). As Figuras 2 e 3, apresentam as respostas dos discentes para a primeira etapa da quarta questão. Nos dois primeiros questionamentos (Figura 2), 
os alunos deveriam escolher e explicar em quais situações a velocidade permanece constante, aumenta ou diminui durante o movimento de revolução na simulação realizada, para se estudar o periélio e o afélio.

Figura 2 - Respostas dos alunos A6 e A15 - Planeta aproximando-se do Sol

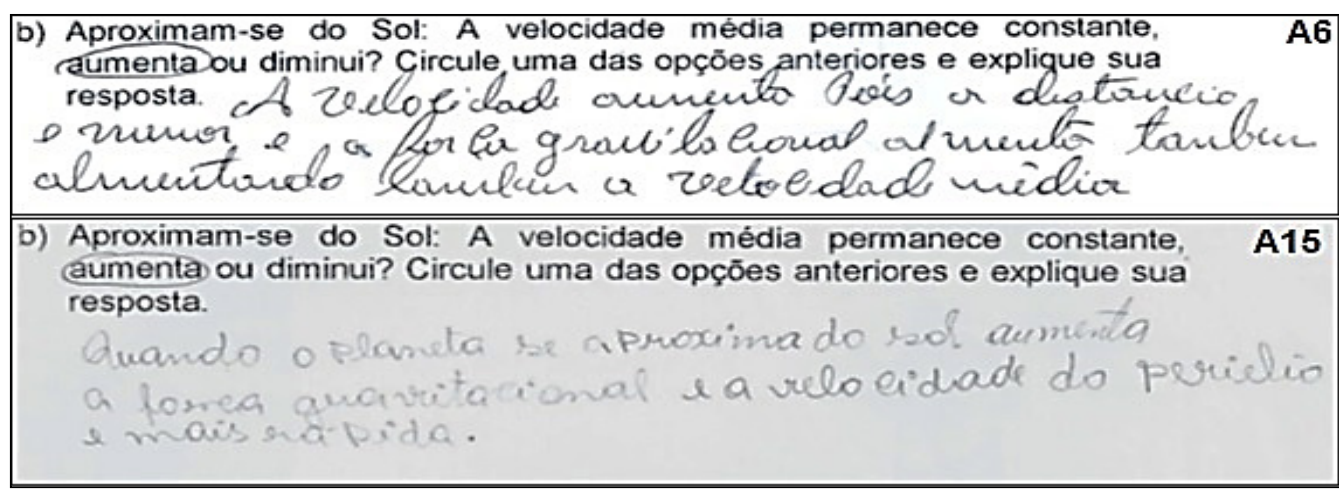

Fonte: Dados da pesquisa.

Figura 3 - Resposta dos Alunos A6 e A15 - Planeta afastando-se do Sol.

\begin{tabular}{|c|c|}
\hline $\begin{array}{l}\text { a) Afastam-se do Sol: A velocidade média permanece } \\
\text { A16 constante, aumenta ou diminui? Circule uma das } \\
\text { opçöes anteriores e explique sua resposta. } \\
\text { Por causa da Foú ongut oriend. } \\
\text { Pa que quando maion a distancia } \\
\text { mena i a frea graritacuinal. ia } \\
\text { relocidat me dia diminui. }\end{array}$ & 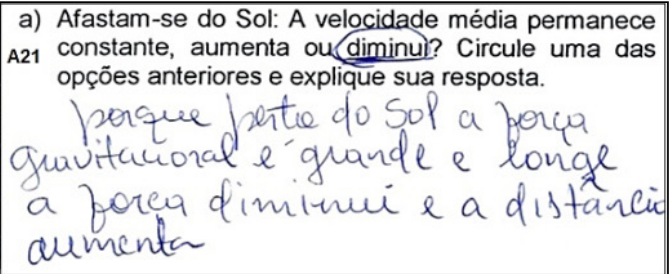 \\
\hline
\end{tabular}

Fonte: Dados da pesquisa.

Conforme Alonso e Finn (1972), para o modelo Sol-Terra, não há a presença da aceleração tangencial. Então, a aceleração resultante no movimento de revolução só apresenta a componente centrípeta, consequentemente a força resultante será centrípeta. Então, essa força resultante é central, e correspondente a força gravitacional entre a Terra e o Sol. Não cabe à força gravitacional a mudança de velocidade orbital. As explicações dos alunos apresentadas nas Figuras 2 e 3, indicam a possibilidade de terem raciocinado que a força gravitacional atuaria como a força tangencial no movimento de revolução da Terra, constituindo o agente motriz para a mudança do valor da velocidade.

Dos trinta partícipes da pesquisa, dezenove alunos responderam a essa questão seguindo o padrão apresentado nas Figuras 2 e 3. Um possível fator que pode explicar essa tendência nas respostas dos discentes é que a maioria dos estudantes em diferentes cursos, níveis e idades, apresentam uma concepção de "força aristotélica", entendendo que sempre deve haver uma força na direção do movimento sendo diretamente proporcional à velocidade. Embora o enfoque dessa 
pesquisa não seja discutir essas concepções de força, é importante notar como os estudantes acionam seus conhecimentos prévios - nesse caso, concepções intuitivas e em desacordo com as leis da Mecânica Clássica - para explicar situações distintas. Caberia aos discentes argumentarem, em função da segunda Lei de Kepler, para justificar o aumento de velocidade no periélio e diminuição no afélio, o que não ocorreu (IBID, 1972). Nesse caso, percebe-se conceitos e relações que precisariam ser melhor explorados para a construção de concepções mais completas e sistêmicas que evidenciam as conexões entre os conceitos.

O último questionamento deste roteiro, ainda em relação as forças de interação entre os planetas e o Sol, solicitava que os alunos optassem entre elas serem de mesma intensidade, maior ou menor, uma em relação a outra. Dezoito alunos apresentaram respostas coerentes com a concepção correta - as forças de atração entre os astros correspondem a pares de ação-reação, de igual intensidade e sentidos contrários, não se cancelando porque são aplicadas em corpos diferentes (os que participam da interação). O aluno A11, ao ler o enunciado, chamou-nos e fez a seguinte pergunta: "Professor, essa aqui é ação e reação né? Depois de tanta força que a gente já viu e calculou aqui, só pode". Argumentações como as dos alunos A1, A11 e A24, respectivamente, nos alicerçam para afirmar que responderam coerentemente: "Mesmos valores, porque tem ação e reação", "São as mesmas forças, ação e reação", "Mesmos valores e têm sentidos opostos baseado na ação e reação". É possível perceber que os estudantes associam a ideia de ação e reação às forças de interação entre uma estrela e um planeta, o que está em acordo com a concepção científica. O Sol e a Terra se atraem mutuamente por meio da atuação da força gravitacional, cujo valor de intensidade e a direção de ação são os mesmos, mas o par de forças apresenta sentidos opostos, o que caracteriza a terceira Lei de Newton (HALLIDAY; RESNICK, 1997).

\section{ANÁLISES DOS DADOS DA SEGUNDA ATIVIDADE - ESTAÇÓES DO ANO}

Para que os alunos pudessem modelar de forma exploratória elipses com diferentes valores de excentricidades, foram realizados inicialmente exercícios de modelagem computacional utilizando o Software Modellus. A ideia foi que comparassem os modelos apresentados em diversos materiais instrucionais com os formatos que se aproximassem da trajetória da Terra ao redor do Sol. Depois, solicitamos que inserissem os valores que correspondem ao semieixo maior $(a) \mathrm{e}$ menor (b) da trajetória elíptica do sistema Terra-Sol, respectivamente, na janela do modelo matemático do Software Modellus (Figura 4). Os termos b e k representam os fatores de translação nas equações da elipse, na forma paramétrica. 
Figura 4 - Modelo computacional das estações do ano e os valores de entrada para a sua execução

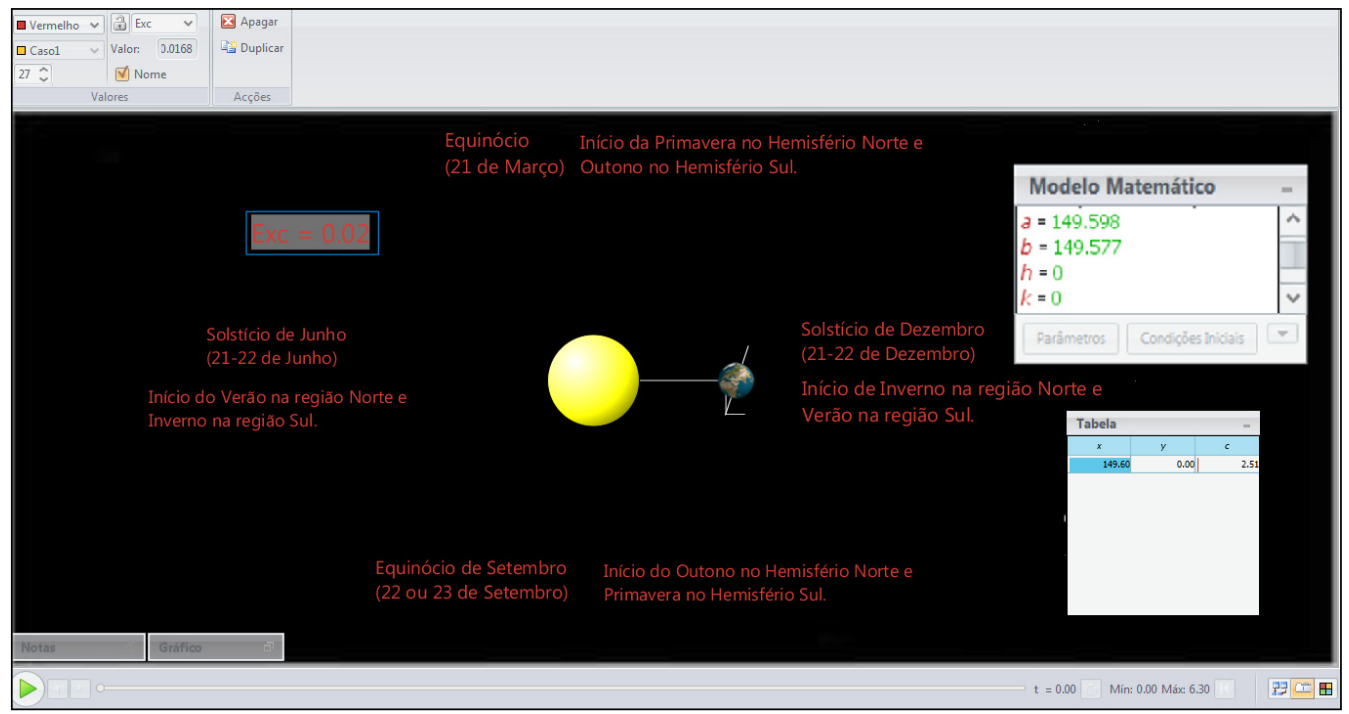

Fonte: do autor.

Solicitamos aos alunos que iniciassem a modelagem, clicando no botão play, no canto inferior esquerdo do Software Modellus e que observassem primeiramente o desenvolvimento da modelagem computacional (Figura 5).

Figura 5-O modelo computacional das estações do ano após sua execução.

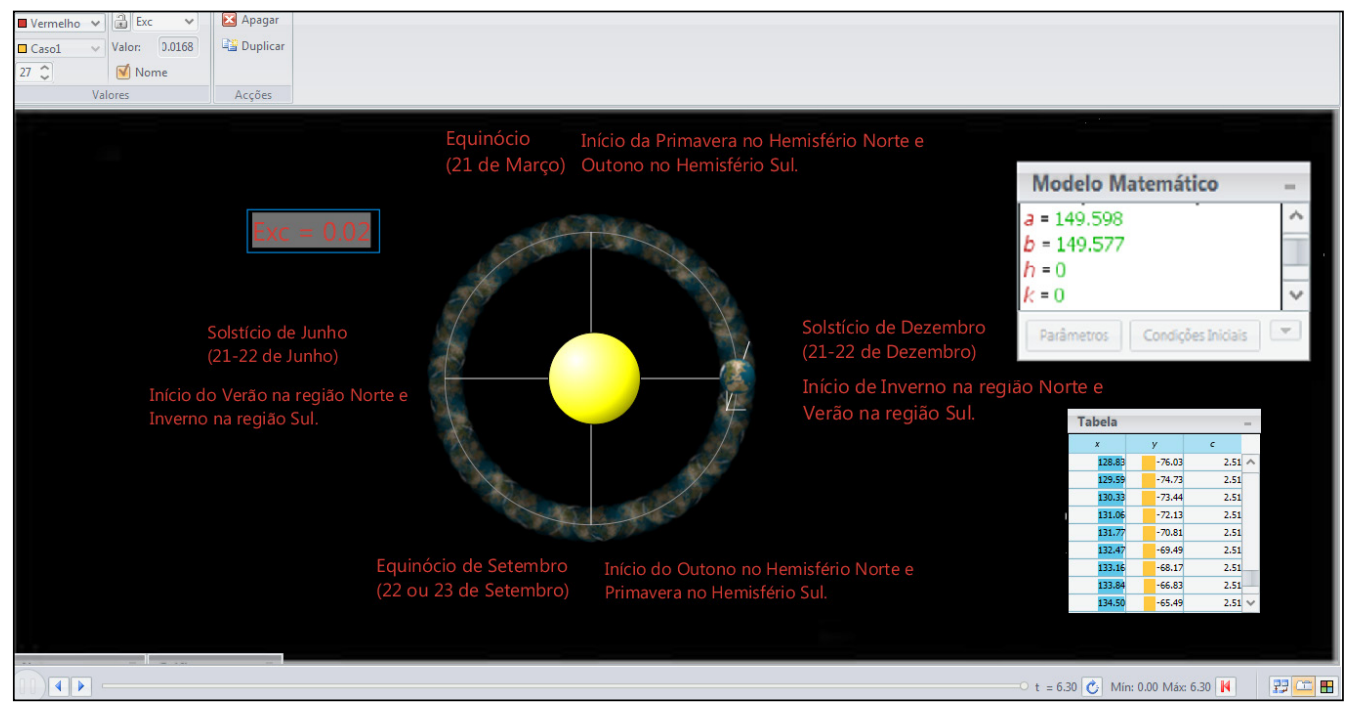

Fonte: do autor. 
É válido destacar que tanto na Figura 4 quanto na Figura 5 o valor da excentricidade da órbita elíptica calculado pelo modelo computacional desenvolvido no Software Modellus, é arredondado $(\mathrm{Exc}=0,02)$. Este valor aparece na área de trabalho do mesmo. Porém, o próprio software apresenta o valor de 0,0168 na barra de menu no canto superior esquerdo, correspondendo ao cálculo realizado conforme os parâmetros matemáticos que originaram o modelo computacional, conforme destacado na Figura 6:

Figura 6 - Valor da excentricidade calculado pelo modelo matemático que suscitou a modelagem computacional das estações do ano no Software Modellus.

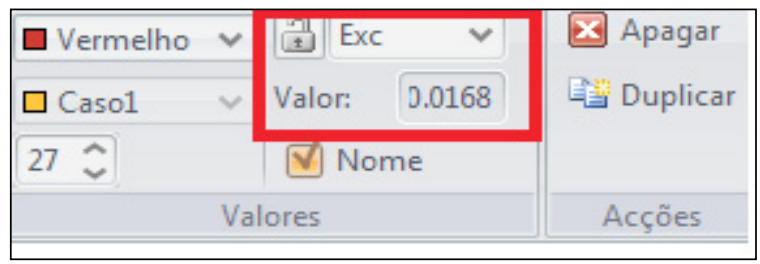

Fonte: do software.

Como já mencionado, para explorar o modelo computacional das Figuras 4 e 5 , elaboramos um roteiro de questões (em anexo), a partir das quais apresentaremos os indícios de aprendizagem dos estudantes. A primeira parte da segunda questão solicitava que desenhassem a forma da trajetória do movimento de revolução da Terra ao redor do Sol e citassem o seu nome. Vinte e um alunos responderam a questão de forma correta. A segunda e a terceira parte dessa questão propôs que os alunos explicassem o motivo da trajetória visualizada na modelagem ser semelhante a uma circunferência. Apresentamos a seguir a resposta do aluno A3 (Figura 7):

Figura 7 - Respostas dos alunos A3 - $2^{\text {a }}$ Questão ( $b$ e c)

b) Explique o porquê da trajetória visualizada na modelagem ser semelhante a uma circunferência.

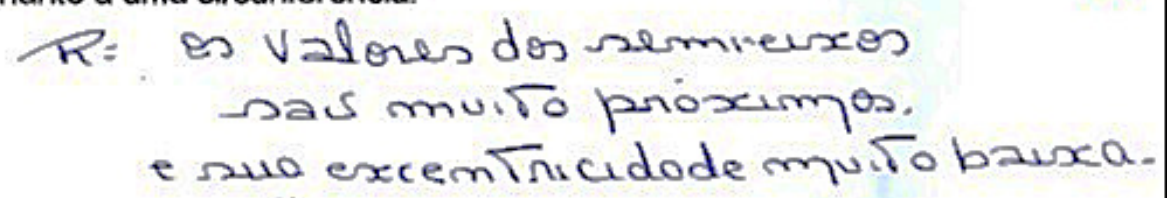

c) Quais os valores alterados na modelagem computacional que ratificam a forma da trajetória da Terra ao redor do Sol? Explique sua resposta.

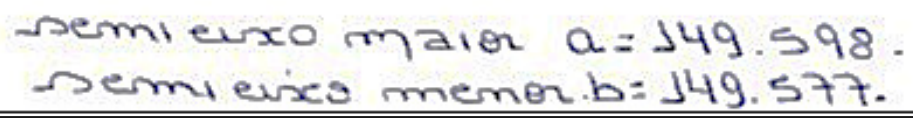

Fonte: dados da pesquisa.

As respostas do aluno $\mathbf{A} \mathbf{3}$ estão coerentes com o modelo científico atualmente aceito, correspondendo ao padrão verificado nas respostas de dezesseis alunos, 
em que conseguiram argumentar e associar o formato da trajetória modelada à excentricidade, e esta com os valores dos semieixos. A terceira questão solicitava que os alunos citassem as estações que iniciam nos solstícios e explicassem o significado dessas datas. Dezessete alunos apresentaram argumentações coerentes com o modelo científico atual. Como exemplo que ilustra o perfil de respostas verificado, apresentamos o argumento do aluno A15: "Solstício é uma data do ano que a cada semestre muda a estação, verão e inverno".

Conforme Uhr (2007), Gonzatti (2008) e Nascimento (2015) as estações inverno e verão têm seus inícios (22/06 e 22/12, aproximadamente) marcados pelos solstícios de inverno e verão, respectivamente, considerando-se o Hemisfério Sul. Enquanto em um Hemisfério da Terra ocorre o inverno para o outro ocorrerá o verão. Sendo assim, as argumentações apresentadas pelos discentes demonstram coerência. A quarta questão solicitava que os alunos respondessem quais estações iniciavam nos equinócios e o significado destas datas. Quatorze deles responderam coerentemente, como é possível perceber nos excertos dos alunos A2, A4 e A12, respectivamente: "É uma data que marca o início da primavera e outono"; "inicia primavera e outono, é uma data que acontece em março ou setembro, acontece a cada 6 meses"; e "Equinócio é o início das estaçôes primavera e outono". As estações outono e primavera têm seus inícios nas datas de equinócios (21/03 e 24/09, aproximadamente, para um observador localizado no hemisfério Sul terrestre) e, pelo fato de nesses dias os raios solares incidirem perpendicularmente em relação ao equador da Terra, ambos os Hemisférios do planeta são iluminados de forma equivalente (GONZATTI, 2008; NASCIMENTO, 2015). As respostas dos alunos transcritas acima, possivelmente indicam a percepção que obtiveram no período que separa um solstício do outro e que o termo caracteriza o início de duas estações em Hemisférios diferentes da Terra.

A quinta questão exigia que os alunos explicassem, em função da duração do dia e da noite, a diferença entre solstícios e equinócios. Apenas doze alunos apresentaram respostas coerentes cientificamente, dentre elas, apresentamos as dos discentes A8, A16 e A30, respectivamente: "solstícios têm mais que o equinócio e o equinócio é igual dia e noite", "Solstícios são diferentes e equinócios iguais" e "equinócio tempo de dia igual a noite, solsticios dias maiores que as noites". As indagações apresentadas pelos alunos indicam que possivelmente os termos solstícios e equinócios correspondem a significações que ainda não haviam sido exploradas em suas vidas estudantis, até o momento da intervenção pedagógica desta pesquisa.

O desempenho dos discentes nesta questão corrobora o fato apontado por Moreira (2011), de um conhecimento prévio especificamente relevante, deve estar presente na estrutura cognitiva dos alunos para que ocorra a aprendizagem significativa. As argumentações dos alunos A8, A16 e A30, que refletem o padrão verificado nas demais, descrevem que nos solstícios ocorrem diferentes durações do período de claridade e escuridão nos hemisférios da Terra e uma igualdade destes períodos nos equinócios. Contudo, conforme o mesmo autor, possivelmente esses conceitos apresentaram-se de forma mecânica, em decorrência da enorme dificuldade demonstrada nas argumentações realizadas pelos alunos. 
No caso do argumento do aluno A30, pode-se perceber que ele sabe que nos solstícios há desigualdade na duração do dia, embora nem sempre os dias sejam maiores que as noites. Isso é correto para o solstício de verão, mas não para o solstício de inverno. A sexta questão foi anulada, pois verificamos algumas similaridades com outras - para Ausubel (2003), deve ser solicitado do aprendiz novas situações de resolução de problemas, para evitar que se resolvam questões por meio da verificação de padrões de soluções. A sétima questão solicitava que os alunos citassem a causa para a ocorrência das estações do ano. Vinte e três alunos argumentaram de forma correta cientificamente e dois não responderam. Apresentamos as respostas dos alunos A2 e A24 (Figura 8), a título de exemplo:

Figura 8 - Resposta dos alunos A2 e A24

7) Qual fator se pode citar como causa para a ocorrència das estaçōes do
ano?
$R=0$ fator responsável pelas estaçös
do ano ia inchinaçäo do liseo da
terra emo? $23,5^{\circ}$.

Fonte: dados da pesquisa.

Nas respostas anteriores, é possível perceber que os alunos assimilaram que a ocorrência das estações do ano na Terra é explicada pela inclinação do eixo terrestre em relação ao plano da translação. Assim como ocorreu na utilização do Software My Solar Systems, percebe-se uma evolução na aprendizagem dos alunos, na temática das estações do ano. Conforme já abordado, um dos erros mais comuns na temática das estações do ano é o de se admitir como causa do fenômeno uma maior ou menor proximidade entre a Terra e o Sol (o modelo das distâncias), não havendo citação por parte dos alunos deste modelo na presente questão.

Um fator a se destacar é que no início da pesquisa (abordagem não focada neste artigo), vinte e três alunos indicaram não conhecer a causa do fenômeno das estações. Agora, ao final da abordagem do tema por meio de diferentes estratégias e materiais didáticos, o mesmo número de discentes demonstra este conhecimento, o que pode ser considerado como um indicativo relevante de aprendizado por parte deles. A oitava questão requeria que os alunos explicassem as características das estações verão e inverno nos diferentes hemisférios da Terra. Dezenove alunos responderam de forma coerente, considerando a influência das latitudes e das diferentes zonas climáticas existentes. A seguir apresentamos a resposta do aluno A2 (Figura 9) como exemplo das recorrentes argumentações fornecidas pelos alunos nesta questão. 
Figura 9 - Resposta do aluno A2

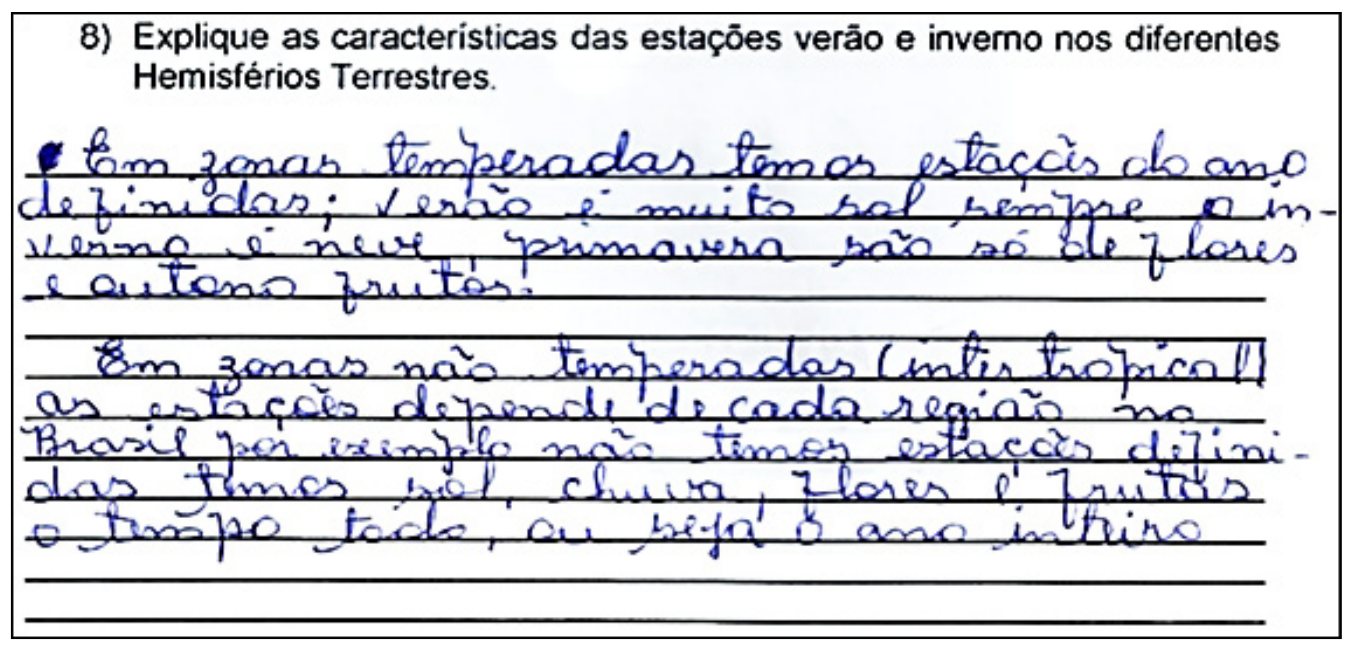

Fonte: dados da pesquisa.

$\mathrm{Na}$ nona questão, foi proposto que os alunos explicassem as características das estações primavera e outono, respectivamente. Quatorze alunos responderam a esta questão segundo uma perspectiva teórica semelhante à utilizada na questão anterior (oitava). A título de exemplo, apresentamos as respostas dos alunos A11, A19 e A26, descritas respectivamente na sequência: "Primavera e outono nas regiões temperadas são bem definidas e fora dessa região existem particularidades do local", "região temperada tem flores, frutas, queda de folha de árvores, onde não é região temperada não tem divisão, depende da região" e "Em zonas como a temperada outono tem fruta e primavera tem flores, nas outras não tem definição". As respostas transcritas pelos discentes nas questões oito e nove demonstram uma evolução em suas concepções sobre o fenômeno das estações. No início da intervenção pedagógica (como detalhado em Nascimento, 2015), vinte e quatro discentes caracterizaram as quatro estações do ano conforme um modelo europeu, ou seja, da mesma forma como ocorrem em regiões de clima temperado: estações bem definidas e com mudanças nas paisagens (SELLES; FERREIRA, 2004).

As argumentações dos discentes indicam que possivelmente estabeleceram a diferença na caracterização das estações em função das regiões analisadas, contrapondo a problemática destacada por Selles e Ferreira (2004), Lima (2006), Nascimento (2015), Nascimento, Neide e Gonzatti (2016): o ensino das estações do ano no Brasil alicerçados em um modelo Europeu. Essa problemática é provocada, em boa medida, pelo fato que ainda, em muitos materiais de ensino utilizados nacionalmente, o fenômeno das estações do território brasileiro é caracterizado de forma equivocada, desconsiderando os diferentes microclimas presentes nesse território. De acordo com Ausubel (2003), as respostas dos alunos podem indicar a ocorrência da diferenciação progressiva, com uma possível evolução conceitual na forma de caracterização das estações do ano. 
A décima questão explorou informações contidas em Kepler e Saraiva (2014) referente ao fato que em janeiro há uma insolação solar maior do que em junho, o que torna as estações do ano mais rigorosas onde se encontra o Brasil, no Hemisfério Sul. Requeria-se dos alunos que explicassem esta afirmativa. Esta questão teve o menor número de acertos, uma vez que apenas dez alunos deram respostas coerentes cientificamente e cinco não responderam. Apresentamos as respostas dos alunos A6, A14 e A22, transcritas de forma respectiva na sequência: "não, por conta do efeito ambiental que contrabalanceia esses 6\%", "Não, no 'bemisfério' sul as estaçoes sofrem interferência dos efeitos ambientais" e "não, o meio ambiente compensará os 6\%".

Conforme Kepler e Saraiva (2014) mesmo em janeiro, com a insolação solar sendo $6 \%$ maior do que em junho, as estações do ano não se tornam mais rigorosas no Hemisfério onde se encontra o Brasil, por conta do contrabalanceamento proporcionado pela maior quantidade de água nesse hemisfério. As respostas dos alunos, transcritas acima, fundamentaram-se em função de fatores ambientais, discutidos nas aulas prévias utilizadas como organizadores prévios.

Novamente sugerimos a obra de Nascimento (2015) para maiores esclarecimentos a cerca desse momento da intervenção pedagógica, em que se encontram todas as etapas detalhadas. Para Moreira (2011), não há como prever se uma determinada atividade utilizada como organizador prévio vai funcionar ou não. Neste caso, mesmo que apenas dez alunos tenham respondido de forma coerente ao questionamento, é possível que as aulas iniciais (organizadores prévios) tenham apresentado algum valor de eficácia nas resoluções apresentadas nesta questão. A décima primeira questão solicitava que os alunos explicassem o motivo de ocorrerem ou não as quatro estações do ano em Belém/PA. Dos trinta participantes da pesquisa, vinte e três alunos responderam de forma coerente cientificamente a questão, como por exemplo, o aluno A24: "Não. Porque não estamos em zona temperada, estamos numa zona indefinida, na verdade temos vários microclimas".

Conforme Selles e Ferreira (2004) e Lima (2006) e Nascimento (2015) as quatro estações do ano com características bem definidas, que as distinguem entre si, são típicas de regiões pertencentes ao Hemisfério Norte, apresentando mudanças na paisagem (clima temperado), nos seres vivos, nos frutos e no florescimento de plantas. Para o Brasil, o mais adequado é a abordagem do fenômeno por meio da associação às regiões do território nacional, haja vista não ocorrerem os contrastes típicos do clima temperado (SELLES; FERREIRA, 2004; NASCIMENTO, 2015). Estas características foram apresentadas pelos respondentes da presente questão, indicando uma possível evolução de aprendizagem na temática em questão.

\section{CONSIDERAÇÓES FINAIS}

Em nossa prática profissional com o público do PROEJA percebemos as dificuldades existentes em relação aos estudos dos fenômenos astronômicos pertencentes ao cotidiano deles, principalmente o das estações do ano. Para auxiliar o processo de ensino de aprendizagem no ensino de Física, nesta temática, propomos a presente pesquisa com a utilização de ferramentas tecnológicas como 
a modelagem e simulação computacional, com o intuito de verificarmos indícios de aprendizagem significativa. Pela interação com os discentes durante toda a intervenção pedagógica e as respostas e argumentações retratadas neste artigo, podemos inferir que este objetivo foi alcançado. Durante as aulas que ocorreram como organizadores prévios ou com as ferramentas tecnológicas, percebemos pelas respostas, argumentações e desenhos feitos, a transição conceitual em termos da evolução dos conhecimentos deles. Em várias situações da intervenção pedagógica foi evidenciada a ocorrência dos processos da reconciliação integradora e da diferenciação progressiva.

Em relação a reconciliação integradora, por exemplo, os alunos estabeleceram uma associação entre a trajetória do movimento de translação da Terra e o formato elíptico de baixa excentricidade, estudados tanto nas atividades de simulação computacional quanto na de modelagem. Outra observação em relação à reconciliação integradora ocorreu pelo fato dos discentes acreditarem que o modelo das distâncias era a causa das estações do ano, no início da intervenção pedagógica. Mas, por meio das atividades desenvolvidas e apresentadas neste artigo, percebemos que os alunos exploraram as relações entre ideias das causas das estações do ano (que eles acreditavam ser a correta e a aceita cientificamente), apontaram similaridades e diferenças importantes e reconciliaram discrepâncias. Assim, indicaram a causa correta cientificamente para o fenômeno das estações: a inclinação do eixo imaginário da Terra, em aproximadamente $23,5^{\circ}$, em relação a normal do plano de revolução ao redor do Sol.

Em relação a diferenciação progressiva, destacamos que, dos trinta alunos participantes da pesquisa, vinte e quatro citaram que no Brasil as quatro estações eram bem definidas, conforme um modelo de estações do ano, apresentado ainda em muitos materiais instrucionais, que enfatizam as características das regiões de clima temperado. Contudo, conseguiram diferenciar progressivamente a concepção de estações do ano, apresentaram uma evolução conceitual sobre o fenômeno das estações para o território brasileiro. Desta forma, foi possível dissertarem que, o mais adequado seria falar em microclimas nas diversas regiões do Brasil e não em quatro estações bem definidas.

Ao fim, sugerimos que as ferramentas tecnológicas utilizadas (modelagem e simulação computacional) atuaram como materiais potencialmente significativos, conforme a teoria de Ausubel (2003).

\section{AGRADECIMENTOS}

O primeiro autor agradece à FAPESB pelo suporte financeiro parcial devido à bolsa de doutorado (BOL170/2015) e o último autor agradece ao CNPq pelo suporte financeiro parcial oriundo de sua bolsa de Produtividade em Pesquisa (No. 304454/2014-1). 


\section{REFERÊNCIAS:}

ALONSO, Marcelo; FINN, Edward J. Física: Um Curso Universitário. Vol. 1

-Mecânica. Editora Edgard Blücher, 1972.

ARAUJO, Ives Solano. Um Estudo sobre o desempenho de alunos de Física usuários da ferramenta computacional Modellus na interpretação de gráficos em cinemática. Porto Alegre: UFRGS, 2002. 111 p. Dissertação (Mestrado) - Programa de Pós-Graduação em Ensino de Física, Instituto de Física, Universidade Federal do Rio Grande do Sul, Porto Alegre, 2002.

ARAUJO, Ives Solano. Simulação e modelagem computacionais como recursos auxiliares no ensino de física geral. Tese (Doutorado em Ensino de Física) - Instituto de Física. Universidade Federal do Rio Grande do Sul, Porto Alegre, 2005.

ARANTES, Alessandra Riposati; MIRANDA, Márcio Santos; STUDART, Nelson. Objetos de aprendizagem no ensino de física: usando simulações do PhET. Física na Escola, 11, n. 1, 27-31, 2010.

AUSUBEL, David Paul. Aquisição e retenção de conhecimento: uma perspectiva cognitiva. Lisboa: Plátano Edições Técnicas, 2003.

BRASIL. Parâmetros Curriculares Nacionais: Ciências da Natureza Matemática e suas tecnologias no ensino médio - SEMTEC/MEC - 1999. Disponível em < http:// portal.mec.gov.br/seb/arquivos/pdf/ciencian.pdf>. Acesso em: 20 de julho 2013.

BARRABIN, M. J. Porqué hay veranos e inviernos? Representaciones de estudiantes (1218) y de futuros maestros sobre algunos aspectos del modelo Sol-Tierra. Ensenanza de las Ciencias, Barcelona, v. 13, n. 2, p. 227-236, 1995.

BAXTER, J. Children's Understanding of Familiar Astronomical Events. International Journal of Science Education, London, v. 11, n. 5, p. 502-513, 1989. Special issue.

BRASIL. Parâmetros Curriculares Nacionais: Ciências da Natureza Matemática e suas tecnologias no ensino médio - SEMTEC/MEC - 1999. Disponível em < http:/ / portal.mec.gov.br/seb/arquivos/pdf/ciencian.pdf>. Acesso em: 08 de mai. 2017.

BRASIL. Ministério da Educação. PROEJA - Programa Nacional de Integração da Educação Profissional com a Educação Básica na modalidade de Educação de Jovens e Adultos. Educação Profissional Técnica de Nível Médio / Ensino Médio. Documento Base. MEC, 2007. Disponível em: <http://portal.mec.gov.br/setec/ arquivos/pdf2/proeja_fundamental_ok.pdf>. Acesso em: 10 ago. 2017.

GONZATTI, Sônia Elisa Marchi. Um Curso Introdutório à Astronomia para a Formação Inicial de Professores de Ensino Fundamental, em nível médio.

Dissertação (Mestrado Profissional em Ensino de Física) - Instituto de Física, Universidade Federal do Rio Grande do Sul, Porto Alegre, 2008.

HALLIDAY, David; RESNICK, Robert. Fundamentos de Física. Companhia Editorial Continental, 1997. 
KEPLER, S. O.; SARAIVA, M. F. O. Oliveira. Astronomia \& Astrofísica. 3. ed. São Paulo: Editora Livraria da Física, 2014. v. 1. 780p.

LIMA, Everaldo José Machado de. A visão do professor de ciências sobre as estações do ano. Dissertação (Mestrado em Ensino de Ciências e Educação Matemática) Universidade Estadual de Londrina. 119f. 2006

MOREIRA, Marco A.; ROSA, Paulo R. S. Subsídios Metodológicos para o professor Pesquisador em Ensino de Ciências. Pesquisa em Ensino: Métodos Qualitativos e Quantitativos. Porto Alegre: Ed. dos Autores, 2009. Disponível em: < http://www. if.ufrgs.br/ moreira/Subsidios11.pdf $>$. Acesso em: 06 de jul. 2014.

MOREIRA, Marco Antônio. O que é, afinal, aprendizagem significativa. Material de apoio aula inaugural do Programa de Pós-Graduação em Ensino de Ciências Naturais. UFMG, Cuiabá, MT, 2010. Disponível em <http://www.if.ufrgs.br/ moreira/ oqueeafinal.pdf>. Acesso em: 19 mar. 2014.

MOREIRA, Marco Antônio. Teorias de aprendizagem. $2^{\mathrm{a}}$ edição. São Paulo, Editora EPU, 2011.

MOREIRA, Marco Antônio. Aprendizagem significativa, organizadores prévios, mapas conceituais, diagramas $\mathrm{V}$ e unidades de ensino potencialmente significativas. I Encontro Regional de Aprendizagem Significativa I ERAS NORTE. UEPA, Belém, 2013. Disponível em: <http://paginas.uepa.br/erasnorte2013/images/ sampledata/figuras/aprend_\%20signif_\%20org_prev_mapas_conc_diagr_v_e_ueps. pdf $>$. Acesso em: 23 abr. de 2014

NARDI, R.; CARVALHO, A. M. P. Um Estudo sobre a Evolução das Noções de Estudantes sobre Espaço, Forma e Força Gravitacional do Planeta Terra. Investigações em Ensino de Ciências, Porto Alegre, v. 1, n. 2, p. 132-144, ago. 1996. Disponível em: < http://core.ac.uk/download/pdf/25767424.pdf>. Disponível em: 14 set. 2015.

NASCIMENTO, Jefferson Oliveira do. A utilização da tecnologia aplicada ao ensino de física: a modelagem computacional das estações do ano por meio do Software Modellus. Monografia de Especialização. UNAMA, Belém, 2014.

NASCIMENTO, Jefferson Oliveira do; NEIDE, Italo Gabriel; GONZATTI, Sônia Eliza Marchi. Modelagem e simulação computacional no ensino de Física: Uma proposta de estudo de caso com o PROEJA. In: XXI Simpósio Nacional de Ensino de Física, 2015, Uberlândia/MG. Anais do XXI SNEF, 2015. v. 1. p. 1-8. Disponível em: < http:// www.sbf1.sbfisica.org.br/eventos/snef/xxi/sys/resumos/T0527-2.pdf $>$. Acesso em: 04 mar. 2015.

NASCIMENTO, Jefferson Oliveira do.; NEIDE, Italo Gabriel.; GOZATTTI, Sônia Elisa Marchi. Objetos de aprendizagem e o Microsoft Excel como ferramentas auxiliares no Ensino de Física. Caderno Pedagógico (online), Lajeado, v. 13, n. 01, 2016. Disponível em: <http://www.univates.br/revistas/index.php/cadped/article/view/990>. Acesso em 02 mai. 2016. 
NUSSBAUM, J. Children's Conceptions of the Earth as a Cosmic Body: a cross age study.Science Education, New York, v. 63, n. 1. p. 83-93, Jan. 1979.

NUSSBAUM, Joseph; NOVAK, Joseph D. An assessment of children's concepts of the earth utilizing structured interviews. Science Education, v. 60, n. 4, p. 535-550, 1976.

PEREIRA, Josué Vidal. O PROEJA no Instituto Federal de Goiás - Campus

Goiânia: Um estudo sobre os fatores de acesso e permanência na escola. Dissertação de Mestrado. Unb. Brasília, 2011.

PARKER. J.; HEYWOOD, D. The Earth and Beyond: developing primary teacher's understanding of basic astronomical events. International Journal of Science Education, London, v. 20, n. 5, p. 503-520, June 1998.

SELLES, Sandra Escovedo; FERREIRA, Marcia Serra. Influências histórico-culturais nas representações sobre as estações do ano em livros didáticos de ciências. Historic-cultural influences about patterns of representantions about seasons in primary school science textbooks. Ciência \& Educação, v. 10, n. 1, p. 101-110, 2004.

SNEIDER, C. I.; OHADI, M. M. Unraveling Students' Misconceptions about the Earth's Shape and Gravity. Science Education, New York, v. 82, n. 2, p. 265-284, Apr. 1998.

TEODORO, Vítor Duarte; NEVES, Rui Gomes. Mathematical modelling in science and mathematics education. Computer Physics Communications, v. 182, n. 1, p. 8-10, 2011.

TIPLER, Paul; MOSCA, Gene. Física: Eletricidade e Magnetismo. Rio de Janeiro, LTC Editora, v. 2, 2006.

VERGARA, Sylvia Constant. Projetos e Relatórios de Pesquisa em Administração. 5 ed. São Paulo: Atlas, 2004. 